\title{
SNPs in Sites for DNA Methylation, Transcription Factor Binding, and miRNA Targets Leading to Allele-Specific Gene Expression and Contributing to Complex Disease Risk: A Systematic Review
}

\author{
Manik Vohra Anu Radha Sharma Navya Prabhu B Padmalatha S. Rai \\ Department of Biotechnology, Manipal School of Life Sciences, Manipal Academy of Higher Education, Manipal, \\ India
}

\section{Keywords}

Complex disease $\cdot$ Single nucleotide polymorphisms . microRNAs · Transcription factors · DNA methylation · Allele-specific gene expression

\begin{abstract}
Introduction: The complex genetic diversity among human populations results from an assortment of factors acting at various sequential levels, including mutations, population migrations, genetic drift, and selection. Although there are a plethora of DNA sequence variations identified through genome-wide association studies (GWAS), the challenge remains to explain the mechanisms underlying interindividual phenotypic disparity accounting for disease susceptibility. Single nucleotide polymorphisms (SNPs) present in the sites for DNA methylation, transcription factor (TF) binding, or miRNA targets can alter the gene expression. The systematic review aimed to evaluate the complex crosstalk among SNPs, miRNAs, DNA methylation, and TFs for complex multifactorial disease risk. Methods: PubMed and Scopus databases were used from inception until May 15, 2019. Initially, screening of articles involved studies assessing the interaction of SNPs with TFs, DNA methylation, or miRNAs resulting in allele-specific gene expression in complex multifactorial diseases. We also included the studies which provided ex-
\end{abstract}

karger@karger.com

(c) 2020 S. Karger AG, Basel

www.karger.com/phg

Karger perimental validation of the interaction of SNPs with each of these factors. The results from various studies on multifactorial diseases were assessed. Results: A total of 11 articles for SNPs interacting with DNA methylation, 30 articles for SNPs interacting with TFs, and 11 articles for SNPs in miRNA binding sites were selected. The interactions of SNPs with epigenetic factors were found to be implicated in different types of cancers, autoimmune diseases, cardiovascular diseases, diabetes, and asthma. Conclusion: The systematic review provides evidence for the interplay between genetic and epigenetic risk factors through allele-specific gene expression in various complex multifactorial diseases.

(c) 2020 S. Karger AG, Basel

\section{Introduction}

The phenotypic variability at the population and individual levels is largely dictated by genetic variations. The study of genetic variations using genome-wide association studies (GWAS) has generated a large amount of data to enable a better understanding of the existing interindividual phenotypic variability. However, the majority of these variations failed to obtain clinical translation with few exceptions, such as exfoliation glaucoma, age-related macular degeneration, and T1DM [1]. Most 


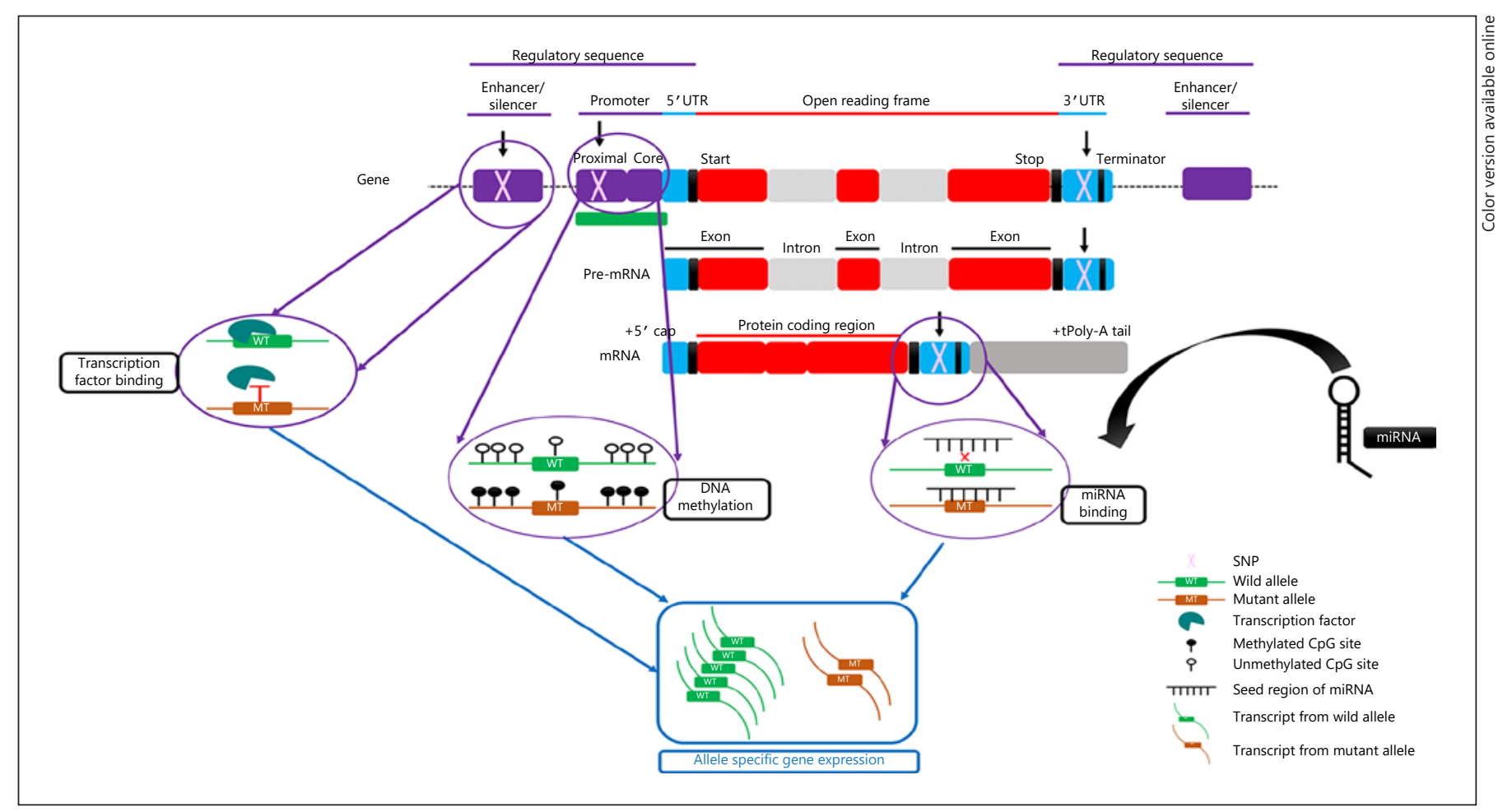

Fig. 1. Interaction of SNPs with TFs, DNA methylation, and miRNA resulting in ASGE. ASGE, allele-specific gene expression; SNPs, single nucleotide polymorphisms; TFs, transcription factors.

frequently, the failure has been attributed to missing heritability and the modest contribution of identified variations in the susceptibility to complex traits [2]. Another possible explanation is that many of the genetic variations, that is, single nucleotide polymorphisms (SNPs), exhibit their effects by interaction with other factors or epigenetic mechanisms, which include DNA methylation, transcription factors (TFs), and miRNAs (Fig. 1). The interaction of SNPs with these epigenetic factors results in the preferential expression of 1 allele, thereby leading to an allele-specific gene expression (ASGE) (Fig. 1). ASGE is a phenomenon by which the product of a gene is exclusively or dominantly transcribed from either of the 2 alleles [3]. The ASGE is a characteristic feature of eukaryotes with diploid genomes, where each gene has 2 copies, one inherited from each parent [3]. There has been an earlier assumption that each allele is expressed alike, thus called bi-allelic expression; however, with studies, many exceptions have come to light [4]. Among them, $\mathrm{X}$ chromosome inactivation (XCI) is the best studied example where transcriptional silencing of 1 $\mathrm{X}$ chromosome in female cells leads to dosage compensation [5]. The unique feature of XCI is that the allele-spe- cific expression (ASE) is chromosome-wide instead of gene specific [5]. The other well-studied example for ASGE is genomic imprinting, which is a phenomenon by which the genes that are expressed in a cell, tissue, or organism follow a parent-of-origin pattern [6]. Genomic imprinting has been observed in human diseases, namely, Prader-Willi syndrome, Angelman syndrome, and male infertility [7-9]. With the advent of sequencing technologies, the understanding of XCI and genomic imprinting has improved [10]. Presently, the ability to quantify the expression of the 2 alleles using RNA sequencing or probe-based methods has led to the observation that the 2 alleles of the same gene exhibit variation in expression output [11].

The phenomenon of ASGE has been attributed to both genetic and epigenetic variations $[12,13]$. The idea that ASGE is heritable and may be implicated in multifactorial human diseases comes from the underlying genetic and epigenetic factors $[12,13]$. The most widely studied genetic variation, which is implicated in interindividual differences, human diseases, and drug response, is SNP [14]. The majority of research was focused on deciphering the functions of SNPs in functional and protein-coding re- 
gions of the genome [12]. GWAS were performed to reveal the interindividual differences in the risk of complex diseases [15]. However, with the advances in the field of epigenetics, the interaction of these SNPs in noncoding regions of the genome with different epigenetic factors such as DNA methylation, miRNAs, and TFs was shown to have a profound impact on phenotypic variations, human diseases, and drug response [16]. According to the present hypothesis, the individual is susceptible to a complex multifactorial disease because of the interaction of genetic variants with environmental factors acting through epigenetic mechanisms. Thus, a proper understanding of the interaction of genetic and epigenetic variations is necessary for unraveling the etiology of common diseases. In the present study, we conducted a systematic review to evaluate the interaction among SNPs, DNA methylation, TFs, and miRNAs for multifactorial disease risk.

\section{Methods}

\section{Literature Search}

A systematic review using PubMed and Scopus databases was performed to select articles highlighting the complex interaction of SNPs with DNA methylation, miRNA, or TFs to result in ASGE in complex multifactorial diseases. The keywords, namely, SNPs, DNA methylation, miRNA, TFs, and ASGE, were used for searching the articles in different combinations. The articles published up to May 2019 were included in the study. The articles were assessed for relevance, and duplicates were removed. The Preferred Reporting Items for Systematic Reviews and Meta-Analyses (PRISMA) guidelines (http://prismastatement.org/) were followed for conducting the systematic review (see online suppl. Table 1; see www.karger.com/doi/10.1159/000510253 for all online suppl. material).

\section{Inclusion and Exclusion Criteria}

The eligibility criteria for including the studies were (a) the study should address the role of the interaction of SNPs with any of the 3 factors, viz., DNA methylation, miRNA, or TFs, to produce ASE; (b) the study must be conducted on human samples, or cells established or derived from humans; (c) it should address the role of SNPs in a multifactorial complex human disease; and (d) the interaction of SNPs with epigenetic factors must be functionally validated. The article search was constrained to the English language. We excluded studies that are focused on rare genetic disorders. The studies which used nonhuman samples for functional characterization or performed only in silico analysis were also excluded from the review. The selected studies were referred for deriving information on identified SNPs, which result in ASGE through DNA methylation, miRNA, or TFs in complex multifactorial human diseases.

\section{Data Extraction and Presentation}

Data extraction was performed in a structured manner by 2 investigators using data collection forms independently, and the duplicates were removed in the end. The studies presented here followed the candidate gene approach. The PRISMA flow diagram is prepared and presented in the results. The extracted data are also presented in the form of concise tables comprising details regarding the studies selected for the present systematic review. The data were classified into 3 parts: (a) SNPs which affect the binding of TFs and lead to ASGE, (b) SNPs which affect DNA methylation to cause ASGE, and (c) SNPs which affect miRNA binding to cause ASGE.

\section{Results and Discussion}

We identified 5,569 and 6,941 entries from PubMed and Scopus sources, respectively, for SNPs interacting with TFs to confer ASGE. For SNPs interacting with DNA methylation, we identified 533 and 9,862 entries from PubMed and Scopus sources, respectively. Similarly, 785 and 705 entries from PubMed and Scopus sources were identified for SNPs, which affect miRNA binding to cause ASGE. After removing duplicates, title, and abstract screening and evaluating the full text in a sequential order, we selected 30 articles for SNPs interacting with TFs, 11 articles for SNPs interacting with DNA methylation, and 11 articles for SNPs in miRNA binding sites (Fig. 2).

\section{SNPs in TF Binding Sites Can Cause ASGE}

The binding of TFs is pivotal for the initiation of the transcription process. SNPs in TF binding sites or motifs can affect the gene regulation process. There are reports of SNPs in TF binding sites in various diseases, such as autoimmune diseases, cancers, cardiovascular diseases (CVDs), and diabetes [17-20].

\section{Disease-Associated with the Immune System}

Asthma is a complex multifactorial disease triggered either by an allergen or sometimes by an autoimmune response [17]. The PHF11 gene was identified as a determinant of serum IgE levels through the positional cloning of human chromosome 13q14 [21]. Holt et al. [22] showed that the A-allele of rs 1046295 has a higher affinity for TF Oct- 1 than the G-allele. The TF Oct-1 is expressed ubiquitously and is involved in both negative and positive regulation of transcription based on the binding site on DNA $[23,24]$. Reports on rs 1046295 highlight the association of the G-allele with asthma and IgE levels [21, 25]. The interaction of rs 1046295 with Oct-1 assigns a regulatory role to the variant in transcription modulation and asthma susceptibility [22]. Furthermore, 2 polymorphisms, namely, rs4065275 and rs8076131, in the ORMDL3 gene were also found to be associated with asthma susceptibil- 


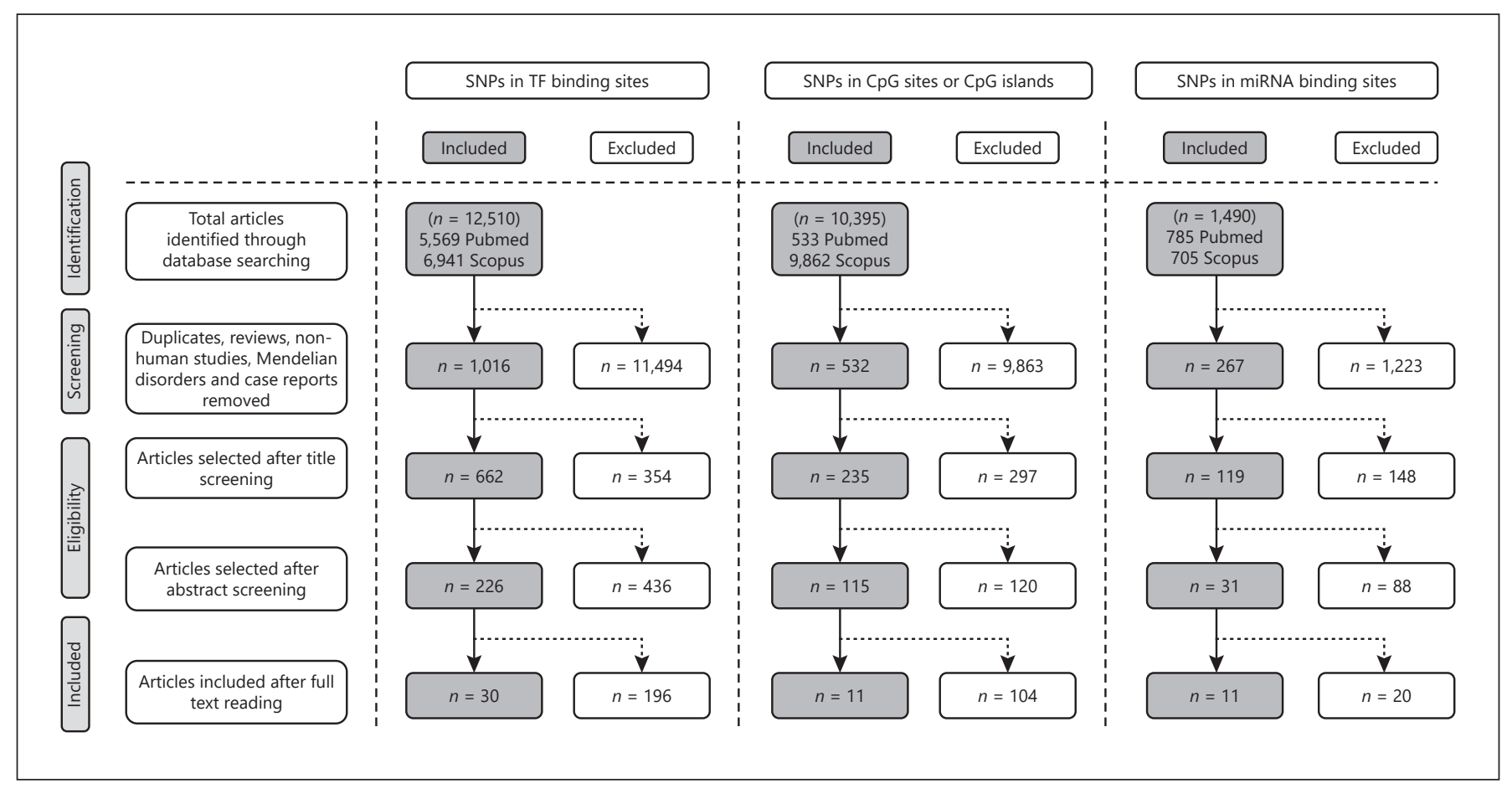

Fig. 2. PRISMA plot for selection of articles. SNPs, single nucleotide polymorphisms; TF, transcription factor; PRISMA, Preferred Reporting Items for Systematic Reviews and Meta-Analyses.

ity [26]. ORMDL3 regulates calcium homeostasis and, in turn, mediates T-cell responses such as Th2 cytokine production [27-30]. The ORMDL3 gene has an important role in the immune response. The presence of risk alleles for rs4065275 and rs8076131 in the gene's regulatory region alters the binding ability of TFs of the SP family and USF1/USF2 complex, respectively [26]. Alternately, the presence of non-risk alleles promotes the binding of SPs and converts USF1/USF2 into a repressor, leading to the lowering of the ORMDL3 gene and, subsequently, the immune response [26].

The variant rs2240032 in the RAD50 gene is linked to atopic disease [31]. The introns of the RAD50 gene are known to harbor cis-regulatory elements for cytokine genes [32]. The variant rs 2240032 is present in the RHS7 gene, which is essential for the T-cell differentiation [33]. Kretschmer et al. [31] showed that rs2240032 modifies the binding of SMAD3 TF. SMAD TFs are well characterized in transforming growth factor- $\beta$ pathways and play an essential role in T-cell growth, function, and differentiation [34]. The causative variant rs2240032 that modifies the SMAD3 binding can regulate the expression of Th2 cytokine genes and skew the immune response. Another variant rs612529 in the VSTM1 gene has been shown to alter the binding of PU.1/YY1 in an allele-specific manner [35]. In monocytes, the expression of the VSTM1 gene is controlled by rs612529, and the presence of C-allele decreases the expression of the gene [35]. The VSTM1 gene inhibits monocyte-derived pro-inflammatory reactions and ROS production. Kumar et al. [35] showed that ROS production through the VSTM1 gene depends on the rs612529 genotype and is also involved in skin homeostasis.

In autoimmune diseases, the differential binding of TFs to candidate SNPs has been indicated as an essential mechanism for gene-to-protein expression [36]. Butter et al. [36] used proteome-wide analysis of the SNPs approach and identified the SNPs in the IL2RA gene, namely, rs12722508, rs12722522, rs41295061, and rs2104286, to alter the binding of RUNX1, LEF1, CREB, and TFAP4 TFs. However, only rs12722508 was validated for allelespecific binding of RUNX1 TF using a reporter assay [36]. Butter et al. [36] suggested that many SNPs in a haplotype may have a cumulative effect on the expression of the gene by the binding of different TFs. In another study, the functional role of rs4794067 in the TBX21 gene is mediated by the binding of YY1 TF, leading to the suppression of the promoter activity [37]. The wild-type T-allele for 
rs4794067 was linked to the risk of systemic lupus erythematosus and protection against HBV infection [37]. The T- and C-alleles of rs4794067 were also evaluated for the effects on human CD4+ T-cell differentiation. In individuals with the $\mathrm{T}$-allele, the $\mathrm{T}$-bet levels were significantly elevated in comparison with the C-allele [37]. T-bet is known to control the IFN- $\gamma$ production and influence the IL-4 levels [38]. Thus, different alleles in the TBX21 gene are speculated in variable Th1/Th2 outcomes [37].

In multiple sclerosis, the CD58 gene variant has been shown to induce higher CD58 mRNA levels and protection from the disease [39]. CD58 stimulates the regulatory $\mathrm{T}$ cells by binding to the $\mathrm{CD} 2$ receptor, which is essential for suppressing autoimmune responses in specific tissues [40]. The C-allele of rs 1335532 creates an enhancer-binding site for Ascl2, which increases the promoter activity of the gene [40]. The increased activity of CD58 is biologically relevant in monocytes as they are attracted to multiple sclerosis lesions [41]. In osteoarthritis, the $5^{\prime}$ UTR methylation and rs143383 on the GDF5 gene were shown to have a combined effect on DEAF1, SP1, and SP3 binding in an allele-specific manner [42]. GDF5 is a signaling molecule for skeletal development. The presence of methylation in the $5^{\prime}$-UTR region of the GDF5 gene and T-allele of rs 143383 represses the gene expression due to the binding of SP1, SP3, and DEAF1 [42]. The expression's shift is toward the C-allele of rs143383, which was observed in the joint tissue [42]. The SOST gene is a regulator of osteoblastic bone formation. Ye et al. [43] showed that SNPs in the SOST gene interact with TFs and miRNA and have possible implications on osteoporosis. Among TFs, FOXA1, MAFF and MAFK, and CTCF binding were observed on rs1230399, rs7220711, and rs1107748 alleles, respectively [43]. The polymorphism rs1230399 influences the binding of FOXA1. The differential FOXA1 binding is implicated in estrogen-induced carcinomas and is important for estrogen receptor-chromatin interactions [44]. FOXA1 is critical for the androgen receptor and estrogen receptor- $\alpha$ [45]. Many studies have shown that testosterone increases and estrogen suppresses the SOST production. The differential binding of estrogen-linked FOXA1 on rs1230399 may be the reason for the altered SOST levels [43]. The polymorphism rs7220711 lies in the enhancer histone marks and is present in the binding site for Maf TFs MAFF and MAFK, whereas rs 1107748 affects the binding of the CTCF-binding element to bring about allele-specific transcription activity in osteoblast cells [43]. The impact of SNP in the SOST gene on miRNA is discussed in the later section. Another SNP, rs6426749 present at 1p36.12, has been linked to osteoporosis [46]. Chen et al. [46] showed that the lncRNA, namely, LINC00339 expression, is regulated by long-range chromatin loop formation mediated by the binding of TFAP2A TF at the rs6426749 G-allele. The LINC00339, in turn, regulates CDC42 expression, which is essential in bone metabolism in osteoblast cells [46].

\section{Cancer}

The impact of SNPs leading to allele-specific binding of TFs has been studied in different types of cancers. In breast cancer, polymorphism in the promoter region of the $E R \beta$ gene has been shown to modulate the binding of YY1 TF [18]. ER $\beta$ plays a vital role in suppressing breast cancer as it is known to regulate ER $\alpha$ activity $[47,48]$ negatively. The expression of the ER $\beta$ gene declines during the progression of breast cancer [49]. Chen et al. [18] showed that the rs1271572 polymorphism present in the $E R \beta$ gene is associated with decreased gene expression. It was also shown that the T-allele for rs1271572 disrupts the binding site for YY1 TF and leads to a reduction in the ER $\beta$ promoter activity [18]. Another gene ODC is known to be involved in polyamine synthesis, which is essential for the development and tissue repair process in mammals [50]. Abnormalities in polyamine metabolism have the potential to promote tumorigenesis [51]. Zell et al. [52] showed that +316 ODC1 SNP is linked to survival in colorectal cancer individuals. They further showed that E-box TFs bind at the SNP site and are associated with allele-specific transcription activity [52]. The A-allele in the reporter elements is associated with higher effects of the activator c-MYC and the repressor MAD1 than the G-allele [52]. A polymorphism rs6983267 at the 8q24.21 locus is a significant cancer-associated SNP and related to colorectal cancer $[53,54]$. Studies have highlighted that the risk allele-G of rs6983267 possess a binding site for TF, namely, TCF4/LEF1, which further leads to the increased transcription of $M Y C[55,56]$. In colorectal cancer, MYC overexpression contributes to the development and progression of colorectal cancer [57]. Moreover, the risk allele-G of rs6983267 is frequently observed in the cancer cells [58]. Sugimachi et al. [59] showed that the development of colorectal cancer requires activation of MYC through the retention of the G-allele of rs6983267.

Allele-specific binding of TFs was observed in Ewing sarcoma, a pediatric malignancy arising from neural crest- or mesoderm-derived stem cells $[60,61]$. The sarcoma is caused by the fusion of EWSR1 and genes in the ETS family $[62,63]$. The fusion results in the formation of an oncogenic TF, which binds to GGAA motifs $[62,64$, 65]. The EGR2 gene expression is increased in Ewing sar- 
coma and associated with variations in the gene [66]. Grünewald et al. [67] showed that the risk allele-A of rs79965208 in the EGR2 gene is linked to adjacent GGAA repeats as it converts a GGAT motif into a GGAA motif. This leads to an increase in EWSR1-FLI1-dependent enhancer activity and increases EGR2 expression in Ewing sarcomagenesis [67].

Gastric cancer is another multifactorial type of cancer influenced by factors such as tobacco addiction, Helicobacter pylori infection, genetic polymorphisms, and exposure to carcinogens [68-70]. The progression of cancer occurs through the remodeling of the extracellular matrix, which is modulated mainly by matrix metalloproteinases (MMPs) [71, 72]. MMP7 is a matrilysin that degrades gelatin, elastin, type IV collagen, vitronectin, fibronectin, laminin, aggrecan, entactin, and proteoglycans $[73,74]$. The MMP7 gene is mainly expressed in tumor tissues $[75,76]$ and is involved in tumor progression by inhibiting apoptosis, inducing angiogenesis, and reducing cell adhesion [77]. Kesh et al. [78] showed that rs11568818 $(-181 \mathrm{~A} \rightarrow \mathrm{G})$ in the $M M P 7$ gene is associated with gastric cancer in the Indian population and the enhanced promoter activity of the G-allele is due to the creation of a binding site for cyclic AMP-response element domain (CREB). They showed that nicotine intake increased the phosphorylation of CRE, and the increased expression of $M M P 7$ is due to the allele-specific binding of pCREB on the MMP7 promoter [78].

Meyer et al. [79] identified a transcriptional regulator element associated with PVT1 gene expression at the $8 \mathrm{q} 24$ locus. They found an SNP, namely, rs378854, present in the DNase I hypersensitive sites, to be a functional variant for prostate cancer [79]. It was observed that YY1 TF binds to the G-allele of rs 378854 and prevents the formation of the DNase I hypersensitive site [79]. The repressor YY1 protein was proposed as a mediator for protection against cancer susceptibility [79]. In another study, Huang et al. [80] showed that the T-allele of rs339331 is involved in the enhanced binding of HOXB13 $\mathrm{TF}$ and can upregulate the RFX6 gene. This was in concordance with the observed expression of the RFX6 gene associated with the $\mathrm{T}$-allele in prostate tumors [80]. RFX6 is involved in the cellular transformation in prostate cancer [80]. RFX6 expression correlates with the severity and progression of prostate cancer [80]. Gao et al. [81] also worked on prostate cancer to identify a regulatory role of rs11672691 in disease progression. It was known that rs11672691 results in fatal prostate cancer. Gao et al. [81] showed the presence of rs11672691 in the enhancer element for HOXA2, which further drives PCAT19 and
CEACAM21 gene expression. The CEACAM21 encodes for a transmembrane protein that belongs to the carcinoembryonic antigen family and is involved in cell invasion, adhesion, and metastasis $[82,83]$. The expression of lncRNA PCAT19 was found to be high in malignant prostate tumors [81]. The G-allele of rs11672691 was shown to enhance the chromatin binding of HOXA2 [81]. This led to elevated expression of PCAT19andCEACAM21[81]. These results provide plausible targets for tailoring therapy and may help in differentiating high-risk group individuals as well.

\section{Cardiovascular Disease}

The concept of allele-specific binding of TFs has been tested for genes involved in CVD risk. The PEAR1 gene codes for the platelet-endothelial aggregation receptor 1 protein which is highly expressed in endothelial cells and platelets [84]. The expression of the PEAR1 gene was associated with rs12041331, a noncoding SNP in platelets [85]. The minor allele-A of rs12041331 attributed to the risk of CVD events [86]. Izzi et al. [19] showed that the rs12041331 G-allele marks the methylation at a CpG island upstream of PEAR1, which leads to the lower affinity of CTCF protein. This further increases the region's enhancer activity harboring rs12041331 and leads to higher gene expression [19]. In the presence of the risk A-allele, the methylation is less, and the CTCF protein binds at the CpG island, and enhancer activity of the site is diminished [19]. GRK2 gene expression has been linked to heart failure, decreased adrenergic signaling, and myocardial contractility [87]. Klenke et al. [88] studied the impact of early growth response 1 (EGR-1) TF, which is involved in cardiovascular pathobiology [89] on GRK2 gene expression. They showed that the promoter region of the GRK2 gene harbors a binding site for EGR-1 TF [88]. They also showed that the polymorphism rs 182084609 is present in the binding site and EGR-1 preferentially binds to the G-allele of rs182084609 [88]. Klenke et al. [88] proposed the inhibition of EGR-1 binding to GRK2 may be useful for adrenergic desensitization.

In the case of hypertension, one of the most widely studied genes is $A G T$, which codes for angiotensinogen involved in the renin-angiotensin system [90]. SNPs in the $A G T$ promoter region are implicated in high blood pressure [91]. Park et al. [90] studied the role of rs5050 in the AGT promoter region and showed that the SNP is present in the E-box sequence which harbors the binding site for USF1 and USF2. However, it was observed that only the $\mathrm{C}$-allele and not A-allele of rs5050 has a higher affinity for USF1 and USF2 TFs [90]. This provided the 
link between the ASE of the AGT gene and USF1 and USF2 TFs [90]. Another variant in the ARHGAP42 gene was linked to blood pressure [92]. The ARHGAP42 gene encodes for Rho-specific GTPase-activating protein which controls muscle contractility in smooth muscle cells [93]. Bai et al. [94] showed that the T-allele of rs604723 present in the intron regulatory element promotes serum response factor binding, which results in the increased expression of ARHGAP42. This provides evidence for the effect of the noncoding variant in the risk of CVDs which might be used for individualizing therapy.

Ischemia is known to induce the accumulation of triacylglycerol in the myocardium [95]. The MTTP gene expression is linked to the concentration of triacylglycerol in the myocardium [95]. MTTP codes for the microsomal triglyceride transfer protein, which is important for the formation of apolipoprotein B [96]. Aminoff et al. [97] showed that the rs1800804 T-allele in the promoter region has a strong affinity for C/EBP TF binding. The Callele lowers the transcriptional activity and increases susceptibility to ischemic heart disease [97]. They proposed that a decrease in MTTP expression results in higher accumulation of lipids, and thus, use of inhibitors for MTTP can increase long-term side effects [97].

Vascular remodeling is the structural rearrangement of blood vessels' walls in response to repair and inflammation [98]. Vascular remodeling is the hallmark for pulmonary arterial hypertension, atherosclerosis, and scleroderma [98]. The NKX2-5 gene involved in the development of blood vessels during embryogenesis $[99,100]$ was also observed in the vessels undergoing remodeling $[101,102]$. Dritsoula et al. [98] showed that the rs3095870 C-allele in the NKX2-5 gene results in allele-specific binding of TEAD1 and YAP1. This leads to transcriptional activation and increases in NKX2 gene expression, which is further associated with features of vascular remodeling $[101,102]$.

\section{Diabetes Mellitus}

Diabetes is a multifactorial condition in humans, which has been linked to several SNPs [103]. The functional impact of many of these SNPs is still unknown. Hiramoto et al. [20] studied the role of rs2074196 in the KCNQ1 gene associated with diabetes and showed that the risk allele for the polymorphism has an allele-specific preference for nuclear transcription factor-Y. SNPs in the TNF- $\alpha$ gene have also been associated with diabetes [104]. Susa et al. [105] showed the IVS1G + 123A polymorphism present in the promoter region aids the recruitment of YY1 and acts to enhance the transcription. This suggested the role of IVS1G + 123A polymorphism as a cis-element in increasing the risk of diabetes [105]. In the islet donors of heterozygous rs3783355 (G/A), an intronic enhancer in the MEG3 gene showed allelic specificity for TFs PDX1, FOXA2, and NKX2.2 [106]. The DLK1$M E G 3$ locus is dysregulated in the islets of diabetes individuals [107]. The suppression of MEG3 increases the susceptibility of $\beta$-cells toward cytokines [106]. The region harboring the variant in the DLK1-MEG3 locus was shown to act as a novel regulatory region in human cells [106].

\section{Other Diseases}

There are examples of allele-specific binding of TFs in Parkinson's disease and chronic fatigue syndrome. Parkinson's disease is a common neurodegenerative disorder that results from the complex multifactorial interaction of environmental and genetic risk factors. The SNCA gene was identified as a strong risk locus in association with Parkinson's disease [108]. Soldner et al. [109] showed rs356168 in the SNCA gene results in allele-specific changes in TF binding sites of EMX2 and NKX6-1 in Parkinson's disease. Functional polymorphisms have been identified in the serotonin receptor 2A (HTR2A) gene in association with chronic fatigue syndrome [110]. Falkenberg et al. [111] showed that rs6311 in the HTR2A gene could disturb both DNA methylation and TF binding (Table 1).

\section{SNPs Affect DNA Methylation Levels, Resulting in} ASGE

DNA methylation in humans occurs predominantly at $\mathrm{CpG}$ sites in the genome and is associated with transcriptional silencing of genes across the genomes. The role of DNA methylation in the etiology of various diseases, namely, cancer, CVDs, type 2 diabetes, and asthma, has been acknowledged [19,111-119]. However, the SNPs nearby or in $\mathrm{CpG}$ sites can either create or abolish CpG site methylation, leading to an alteration in the expression of the genes. Moreover, it has also been shown that changes in methylation of one CpG site can influence the methylation levels of flanking $\mathrm{CpG}$ sites. In the literature, there are some examples where SNPs in the methylation sites affect the methylation levels and result in differential allelic expression.

A polymorphism rs 2240032 in the RAD50 gene on chromosome $5 \mathrm{q} 31$ previously associated with asthma affects methylation of the downstream located IL13 promoter region [119]. Schieck et al. [119] showed that locus can influence DNA methylation and has an impact on IgE levels in children. 


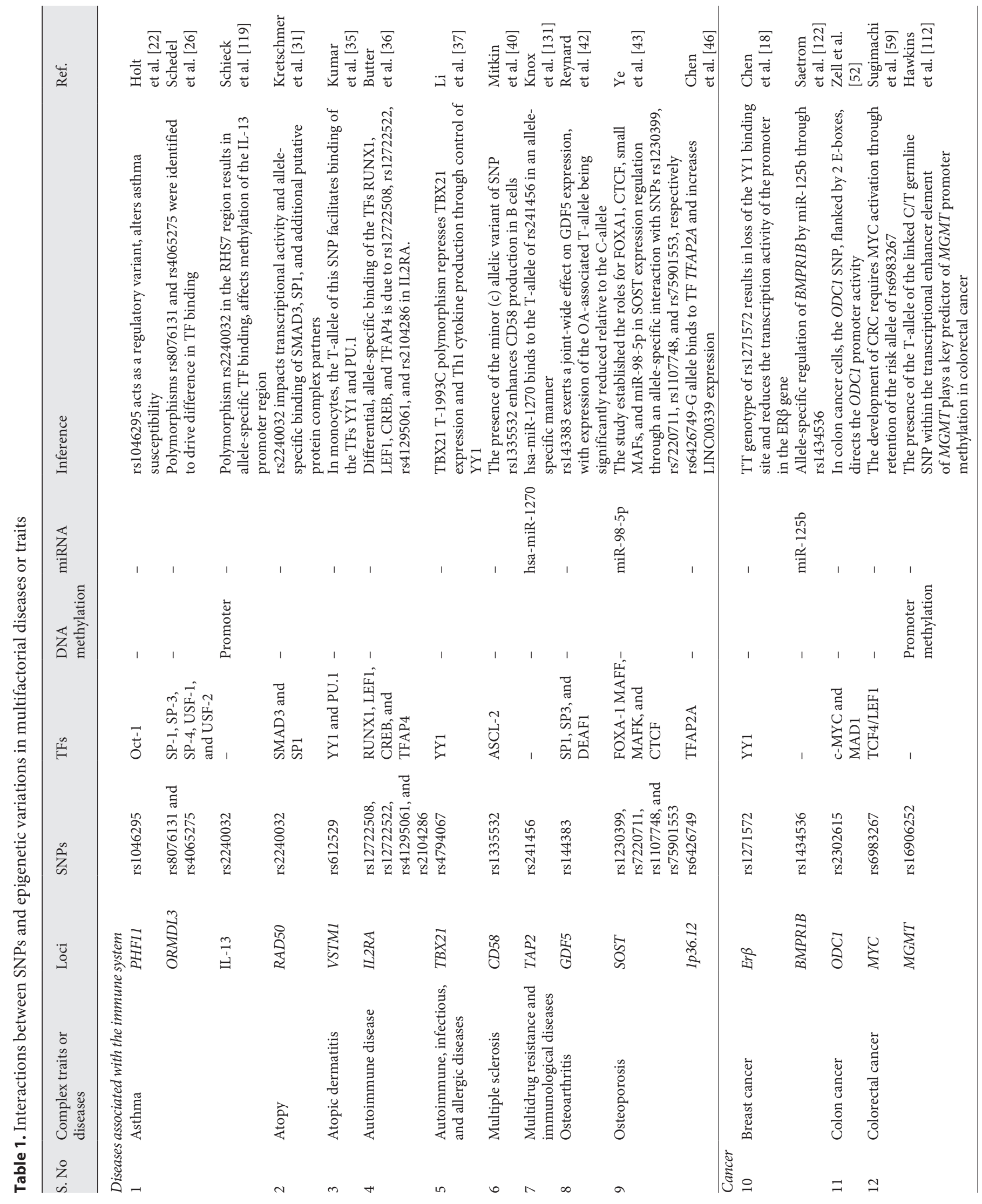




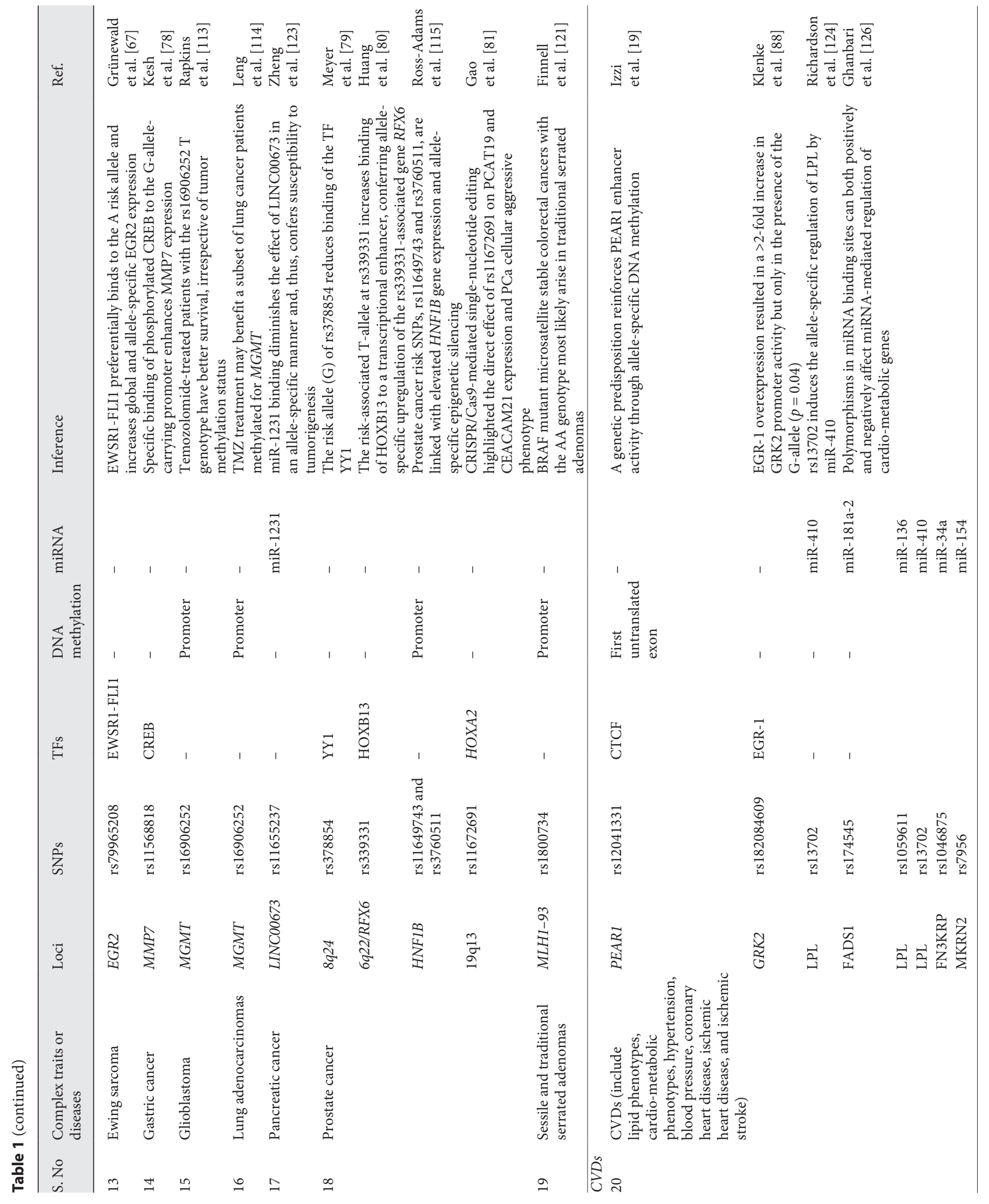




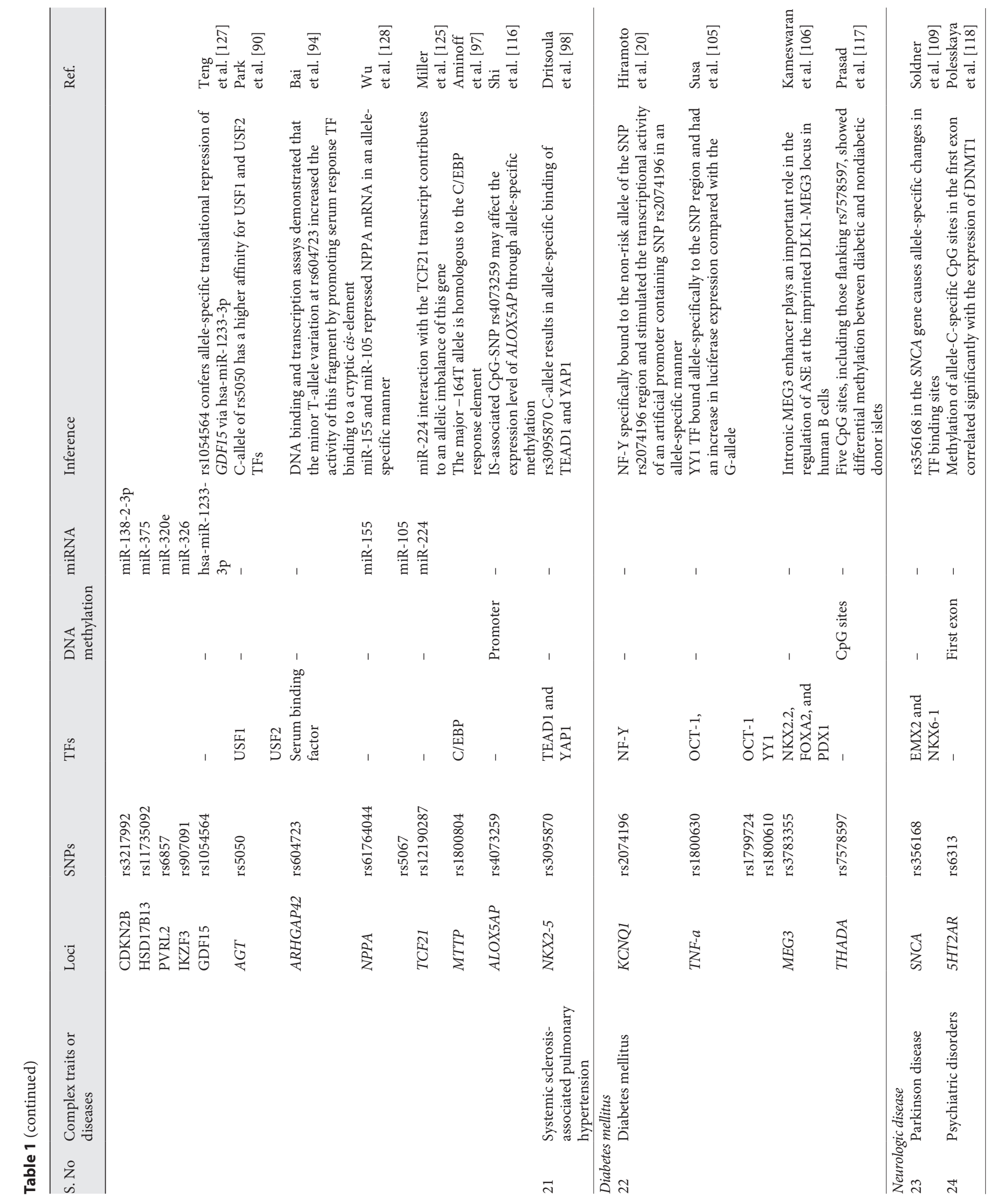




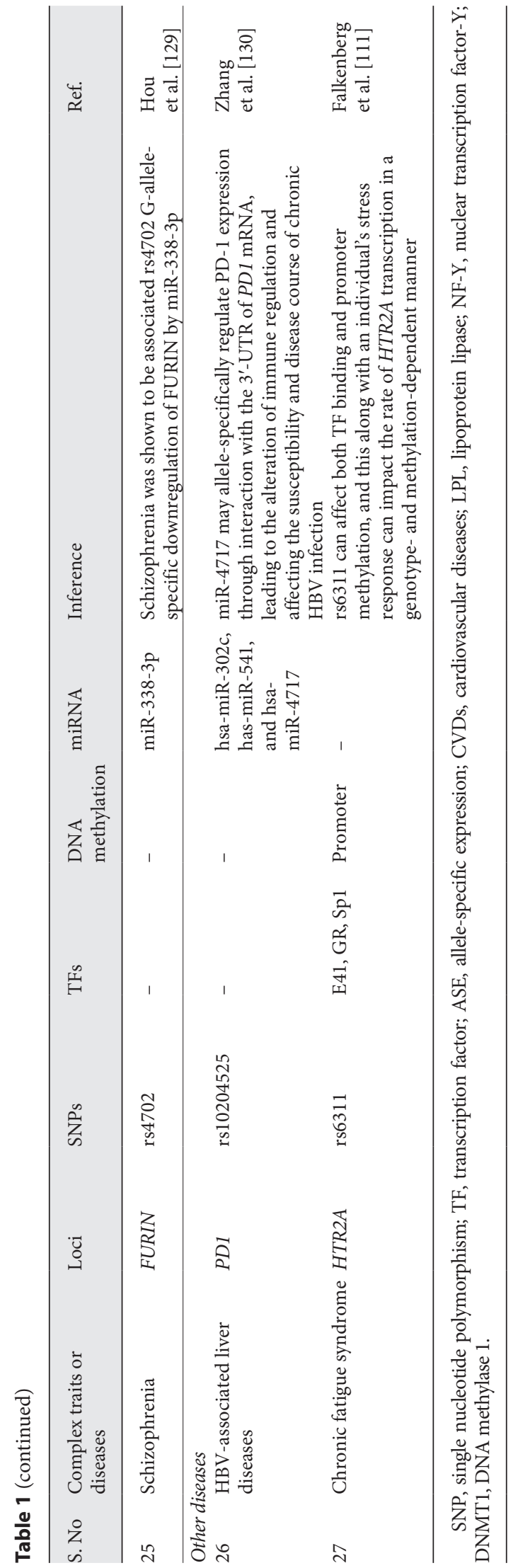

ASE in Multifactorial Diseases
MGMT codes for a DNA repair protein and is frequently methylated in sporadic colorectal cancer [112]. However, MGMT promoter methylation is influenced by a cis-acting rs 16906252 present within the transcriptional enhancer element in colorectal cancer, glioblastoma, and lung adenocarcinoma [112-114]. The HNF1B gene plays a major role in the development of ovarian and prostate cancers [115]. rs11649743 and rs3760511 in the HNF1B gene were shown to be associated with allele-specific epigenetic silencing in prostate cancer [115]. A mismatch repair protein is coded by the $M L H 1$ gene, and loss of its expression is implicated in microsatellite instability [120]. In sessile and traditional serrated adenomas, a minor Aallele of rs1800734 was associated with increased methylation levels in $M L H 1$ promoter [121].

In the case of CVDs, the PEAR1 gene and ALOX5AP gene have been associated with the disease $[19,116]$. PEAR1, as discussed earlier, plays a role in cardiovascular events. The ALOX5AP gene codes for 5-lipoxygenase-activating protein and is a risk factor for ischemic stroke. Two CpG SNPs, namely, rs12041331 in the PEAR1 gene and rs4073259 in the ALOX5AP gene, affect the expression of genes through allele-specific methylation and contribute to platelet reactivity and ischemic stroke, respectively $[19,116]$.

In type 2 diabetes, among the known SNPs for disease susceptibility, rs7578597 in the THADA gene showed parent-of-origin expression and was linked to differential methylation of 2 flanking CpG sites near to the SNP [117]. Allele-specific methylation has also been observed in genes associated with psychiatric disorders and chronic fatigue syndrome. SNPs, namely, rs6311 and rs6313, present in the promoter and first exon, respectively, are shown to have allele-C-specific methylation in psychiatric disorders and chronic fatigue syndrome [111, 118] (Table 1). These reports provide evidence for the role of methylation in driving ASE complex phenotypes.

\section{SNPs in miRNA Target Sites Cause Differential Allelic Expression}

miRNAs are known to regulate gene expression by binding to the $3^{\prime}$-UTR region of the gene. For years, it has been thought that changes in the target sequence can result in improper binding of miRNA and lead to dysregulated gene expression. This has been, at times, supported by evaluations in normal physiological conditions and in different types of cancer. A polymorphism in the $B M$ $P R 1 B$ gene, that is, rs1434536 (C>T) associated with breast cancer, was found to be present in the binding site of miR-125b [122]. It was shown that miR-125b binds to 
the $\mathrm{C}$-allele and results in allele-specific regulation of the $B M P R 1 B$ gene [122]. In the case of pancreatic cancer, a polymorphism rs11655237 in the LINC00673 gene was shown to affect the miR-1231 binding in an allele-specific manner and thus lead to susceptibility to cancer [123].

SNPs associated with other complex diseases such as CVDs have also affected miRNA binding. For example, rs13702 (T>C) leads to allele-specific regulation of the lipoprotein lipase $(L P L)$ gene by miR-410, with miRNA having a more binding affinity for the T-allele [124]. TCF21 rs12190287 associated with coronary heart disease interacts with miR-224 and induces an allelic imbalance of the TCF21 gene [125]. A comprehensive study on cardiometabolic phenotypes showed $7 \mathrm{SNP}$ and miRNA pairs, namely, rs1059611 (LPL:miR-136), rs174545 (FADS1:miR-181a-2), rs13702 (LPL:miR-410), rs7956 (MKRN2:miR-154), $\quad$ rs1046875 (FN3KRP:miR-34a), rs11735092 (HSD17B13:miR-375), and rs3217992 (CDKN2B:miR-138-2-3p), which abolish miRNA-dependent gene regulation [126]. This study also showed 2 SNP and miRNA pairs, namely, rs907091 (IKZF3:miR-326) and rs6857 (PVRL2:miR-320e), which create the binding site for miRNAs and thus induce miRNA-dependent gene regulation [126]. Another study showed allele-specific translational suppression by miR-1233-3p binding to the G-allele of the rs1054564 GDF15 gene, which is a strong predictor of CVD events [127]. The NPPA gene that encodes for atrial natriuretic peptide involved in regulating blood pressure was shown to be regulated by $\mathrm{miR}$ 155 and miR-105 in an allele-specific manner, affecting wild alleles of rs61764044 and rs5067, respectively [128].

Apart from CVDs, rs4702 FURIN gene polymorphism identified as cis-expression quantitative trait loci in association with schizophrenia is shown to be regulated by miR-338-3p [129]. Furthermore, the downregulation of the FURIN gene has been shown to reduce the maturation of brain-derived neurotrophic factor in schizophrenia [129]. Other gene polymorphisms, rs10204525 PD1 and rs241456 TAP2, are present in the binding site for miR4717 and miR-1270, respectively [130, 131]. These polymorphisms have been implicated in immune regulation and immunological diseases (Table 1).

\section{Future Directions}

Studies can consider the characterization of known GWAS-associated variations, which can potentially affect epigenetic patterns and regulate gene expression, as a starting point to conclusively determine the role of vari- ants as a determinant of multifactorial human disease. Precisely, the identification of SNPs in potential TF binding sites, DNA methylation, and miRNA binding sites must be pursued in a high-throughput and cost-effective manner to illustrate the effects of imbalance in RNA transcripts for disease risk. However, SNPs' proper characterization in potential $\mathrm{T}$ binding sites, DNA methylation, and miRNA binding sites remains a significant challenge [132]. This is major because all epigenetic changes show tissue specificity [133]. Therefore, the evaluation of these interactions in different tissues becomes essential. The effect of environmental exposures may also influence the levels of TFs, DNA methylation, and miRNAs [134] and, thus, is critical for deriving proper conclusions. Last, upcoming high-throughput sequencing technologies may be considered for simultaneous evaluations of a large number of samples [135]. Finally, the patterns of SNP segregation and prevalence in different ethnic groups are thought to inflict a complex phenotype through different environmental exposures and epigenetic modulations. These interactions between SNPs and disease susceptibility may be evaluated in different ethnic groups [136]. Nonetheless, the present study's analysis highlights the information in hand regarding complex human diseases and compiles the different results obtained from different evaluations. This forms the present study's strength and provides compelling evidence for future evaluations of complex phenotypes and traits.

\section{Conclusion}

The genetic variants identified through GWAS or a candidate gene approach concerning multifactorial complex human phenotypes or diseases show accumulating evidence of interaction with TFs, DNA methylation, and miRNA to confer ASGE and, hence, result in increased susceptibility to diverse diseases [132]. The investigations which have studied the crosstalk of SNPs with TFs, DNA methylation, and miRNA have shown both positive and negative effects in various pathologies [132, 137]. The SNPs in promoter or $5^{\prime}$-UTR regions have been shown to inflict or abolish TF binding sites, leading to an aberrant increase or decrease in transcripts from an allele [138]. Similarly, SNPs in CpG sites can create or destroy the methylation sites and act as a cis-acting factor for methylation of flanking $\mathrm{CpG}$ sites and can potentially alter proper binding of TFs as well [139]. miRNA interacts with SNPs in various locations of the gene and regulates gene expression in an allele-specific manner. These inter- 
actions result in a subsequent change in the allelic dose, which seems to play an essential role in disease risk. Wang et al. [132] have postulated this phenomenon as a working model and termed it as an "SNP intensifier." With the existing evidence in hand, the future targets should be to test the mechanisms by which SNPs contribute to susceptibility for complex human phenotypes or traits.

\section{Statement of Ethics}

The authors have no ethical conflicts to disclose. The present study is a systematic review; hence, no ethical clearance was obtained.

\section{Conflict of Interest Statement}

The authors have no conflicts of interest to declare.

\section{Funding Sources}

This review paper received no specific grant from any funding body

\section{Author Contributions}

Formulation of the research and research questions: Manik Vohra and Padmalatha S. Rai. Study design: Manik Vohra, Anu Radha Sharma, and Padmalatha S. Rai. Carrying out the study: Manik Vohra, Anu Radha Sharma, and Navya Prabhu B. Writing the manuscript: Manik Vohra and Anu Radha Sharma. Proofreading and editing: Manik Vohra, Anu Radha Sharma, Navya Prabhu B, and Padmalatha S. Rai.

\section{References}

1 Manolio TA. Bringing genome-wide association findings into clinical use. Nat Rev Genet. 2013;14(8):549-58.

2 Manolio TA, Collins FS, Cox NJ, Goldstein DB, Hindorff LA, Hunter DJ, et al. Finding the missing heritability of complex diseases. Nature. 2009;461(7265):747-53.

3 Benitez JA, Cheng S, Deng Q. Revealing allele-specific gene expression by single-cell transcriptomics. Int J Biochem Cell Biol. 2017;90:155-60.

4 Eckersley-Maslin MA, Spector DL. Random monoallelic expression: regulating gene expression one allele at a time. Trends Genet. 2014;30(6):237-44.

5 Plath K, Mlynarczyk-Evans S, Nusinow DA, Panning B. Xist RNA and the mechanism of $\mathrm{X}$ chromosome inactivation. Annu Rev Genet. 2002;36(1):233-78.

6 Sakatani T, Wei M, Katoh M, Okita C, Wada D, Mitsuya K, et al. Epigenetic heterogeneity at imprinted loci in normal populations. Biochem Biophys Res Commun. 2001;283(5): 1124-30.

7 Alexander RC. Prader-Willi syndrome. In: Rubin L, Merrick J, Greydanus DE, Patel DR, editors. Health care for people with intellectual and developmental disabilities across the lifespan. 3rd ed. Cham: Springer International Publishing AG; 2016. p. 779-98.

8 Greydanus DE, Pratt HD, Pryson M. Angelman syndrome. In: Rubin L, Merrick J, Greydanus DE, Patel DR, editors. Health care for people with intellectual and developmental disabilities across the lifespan. 3rd ed. Cham: Springer International Publishing AG; 2016. p. 815-9.
9 Rotondo JC, Selvatici R, Di Domenico M, Marci R, Vesce F, Tognon M, et al. Methylation loss at H19 imprinted gene correlates with methylenetetrahydrofolate reductase gene promoter hypermethylation in semen samples from infertile males. Epigenetics. 2013;8(9):990-7.

10 Wang Q, Li K, Zhang D, Li J, Xu G, Zheng J, et al. Next-generation sequencing techniques reveal that genomic imprinting is absent in day-old gallus gallus domesticus brains. PLoS One. 2015;10(7):e0132345.

11 Kukurba KR, Montgomery SB. RNA sequencing and analysis. Cold Spring Harb Protoc. 2015;2015(11):951-69.

12 Buckland PR. Allele-specific gene expression differences in humans. Hum Mol Genet. 2004; 13 Spec No 2(2):R255-60.

13 Knight JC. Allele-specific gene expression uncovered. Trends Genet. 2004;20(3):113-6.

14 Shastry BS. SNPs in disease gene mapping, medicinal drug development and evolution. J Hum Genet. 2007;52(11):871-80.

15 Sebastiani P, Timofeev N, Dworkis DA, Perls TT, Steinberg MH. Genome-wide association studies and the genetic dissection of complex traits. Am J Hematol. 2009;84(8):504-15.

16 Zaina S, Pérez-Luque EL, Lund G. Genetics talks to epigenetics? The interplay between sequence variants and chromatin structure. Curr Genomics. 2010;11(5):359-67.

17 Tedeschi A, Asero R. Asthma and autoimmunity: a complex but intriguing relation. Expert Rev Clin Immunol. 2008;4(6):767-76.

18 Chen L, Liang Y, Qiu J, Zhang L, Chen X, Luo $\mathrm{X}$, et al. Significance of rs1271572 in the estrogen receptor beta gene promoter and its correlation with breast cancer in a southwestern Chinese population. J Biomed Sci. 2013;20(1):32.
19 Izzi B, Pistoni M, Cludts K, Akkor P, Lambrechts D, Verfaillie C, et al. Allele-specific DNA methylation reinforces PEAR1 enhancer activity. Blood. 2016;128(7):1003-12.

20 Hiramoto $\mathrm{M}$, Udagawa $\mathrm{H}$, Watanabe $\mathrm{A}$, Miyazawa K, Ishibashi N, Kawaguchi M, et al. Comparative analysis of type 2 diabetes-associated SNP alleles identifies allele-specific DNA-binding proteins for the KCNQ1 locus. Int J Mol Med. 2015;36(1):222-30.

21 Zhang Y, Leaves NI, Anderson GG, Ponting $\mathrm{CP}$, Broxholme J, Holt R, et al. Positional cloning of a quantitative trait locus on chromosome 13q14 that influences immunoglobulin E levels and asthma. Nat Genet. 2003; 34(2):181-6.

22 Holt RJ, Zhang Y, Binia A, Dixon AL, Vandiedonck C, Cookson WO, et al. Allele-specific transcription of the asthma-associated PHD finger protein 11 gene (PHF11) modulated by octamer-binding transcription factor 1 (Oct1). J Allergy Clin Immunol. 2011;127(4): 1054-2.

23 Mordvinov VA, Schwenger GT, Fournier R, De Boer ML, Peroni SE, Singh AD, et al. Binding of YY1 and Oct1 to a novel element that downregulates expression of IL-5 in human T cells. J Allergy Clin Immunol. 1999;103(6): 1125-35.

24 Salerno MS, Schwenger GT, Sanderson CJ, Mordvinov VA. Binding of octamer factors to the murine IL-5 CLE0 in primary T-cells and a T-cell line. Cytokine. 2001;15(1):4-9.

25 Gao J, Li W, Willis-Owen SA, Jiang L, Ma Y, Tian X, et al. Polymorphisms of PHF11 and DPP10 are associated with asthma and related traits in a Chinese population. Respiration. 2009;79(1):17-24. 
26 Schedel M, Michel S, Gaertner VD, Toncheva AA, Depner M, Binia A, et al. Polymorphisms related to ORMDL3 are associated with asthma susceptibility, alterations in transcriptional regulation of ORMDL3, and changes in $\mathrm{TH} 2$ cytokine levels. J Allergy Clin Immunol. 2015;136(4):893-903.e14.

27 Carreras-sureda A, Cantero-recasens G, Rubio-moscardo F, Kiefer K, Peinelt C, Niemeyer BA, et al. ORMDL3 modulates store-operated calcium entry and lymphocyte activation. Hum Mol Genet. 2013;22(3):519-30.

28 Cantero-Recasens G, Fandos C, Rubio-Moscardo F, Valverde MA, Vicente R. The asthma-associated ORMDL3 gene product regulates endoplasmic reticulum-mediated calcium signaling and cellular stress. Hum Mol Genet. 2009;19(1):111-21.

29 Lewis RS. Calcium signaling mechanisms in Tlymphocytes. Annu Rev Immunol. 2001; 19(1):497-521.

30 Weber KS, Miller MJ, Allen PM. Th17 cells exhibit a distinct calcium profile from Th1 and Th2 cells and have Th1-like motility and NF-AT nuclear localization. J Immunol. 2008; 180(3):1442-50.

31 Kretschmer A, Möller G, Lee H, Laumen H, Von Toerne C, Schramm K, et al. A common atopy-associated variant in the Th2 cytokine locus control region impacts transcriptional regulation and alters SMAD3 and SP1 binding. Allergy. 2014;69(5):632-42.

32 Wilson CB, Rowell E, Sekimata M. Epigenetic control of T-helper-cell differentiation. Nat Rev Immunol. 2009;9(2):91-105.

33 Lee GR, Spilianakis CG, Flavell RA. Hypersensitive site 7 of the TH2 locus control region is essential for expressing $\mathrm{TH} 2$ cytokine genes and for long-range intrachromosomal interactions. Nat Immunol. 2005;6(1):42-8.

34 Li MO, Wan YY, Sanjabi S, Robertson AK, Flavell RA. Transforming growth factor-beta regulation of immune responses. Annu Rev Immunol. 2006;24(1):99-146.

35 Kumar D, Puan KJ, Andiappan AK, Lee B, Westerlaken GH, Haase D, et al. A functional SNP associated with atopic dermatitis controls cell type-specific methylation of the VSTM1 gene locus. Genome Med. 2017;9(1):18.

36 Butter F, Davison L, Viturawong T, Scheibe M, Vermeulen M, Todd JA, et al. Proteomewide analysis of disease-associated SNPs that show allele-specific transcription factor binding. PLoS Genet. 2012;8(9):e1002982.

37 LiJR, Li JG, Deng GH, Zhao WL, Dan YJ, Wang $\mathrm{YM}$, et al. A common promoter variant of TBX21 is associated with allele specific binding to Yin-Yang 1 and reduced gene expression. Scand J Immunol. 2011;73(5):449-58.

38 Mowen KA, Glimcher LH. Signaling pathways in Th2 development. Immunol Rev. 2004;202:203-22.

39 De Jager PL, Baecher-Allan C, Maier LM, Arthur AT, Ottoboni L, Barcellos L, et al. The role of the CD58 locus in multiple sclerosis. Proc Natl Acad Sci U S A. 2009;106(13):52649.
40 Mitkin NA, Muratova AM, Korneev KV, Pavshintsev VV, Rumyantsev KA, Vagida MS, et al. Protective $C$ allele of the single-nucleotide polymorphism rs1335532 is associated with strong binding of Ascl2 transcription factor and elevated CD58 expression in B-cells. Biochim Biophys Acta Mol Basis Dis. 2018;1864(10):3211-20.

41 Morandi E, Tarlinton RE, Gran B. Multiple sclerosis between genetics and infections: human endogenous retroviruses in monocytes and macrophages. Front Immunol. 2015;6: 647.

42 Reynard LN, Bui C, Syddall CM, Loughlin J. $\mathrm{CpG}$ methylation regulates allelic expression of GDF5 by modulating binding of SP1 and SP3 repressor proteins to the osteoarthritis susceptibility SNP rs143383. Hum Genet. 2014;133(8):1059-73.

43 Ye W, Wang Y, Mei B, Hou S, Liu X, Wu G, et al. Computational and functional characterization of four SNPs in the SOST locus associated with osteoporosis. Bone. 2018;108: $132-44$.

44 Laganière J, Deblois G, Lefebvre C, Bataille AR, Robert F, Giguère V. From the cover: location analysis of estrogen receptor alpha target promoters reveals that FOXA1 defines a domain of the estrogen response. Proc Natl Acad Sci U S A. 2005;102(33):11651-6.

45 Robinson JL, Holmes KA, Carroll JS. FOXA1 mutations in hormone-dependent cancers. Front Oncol. 2013;3:20.

46 Chen XF, Zhu DL, Yang M, Hu WX, Duan YY, Lu BJ, et al. An osteoporosis risk SNP at $1 p 36.12$ acts as an allele-specific enhancer to modulate LINC00339 expression via longrange loop formation. Am J Hum Genet. 2018;102(5):776-93.

47 Chen L, Qiu J, Yang C, Yang X, Chen X, Jiang $\mathrm{J}$, et al. Identification of a novel estrogen receptor beta1 binding partner, inhibitor of differentiation-1, and role of ERbeta1 in human breast cancer cells. Cancer Lett. 2009;278(2): 210-9.

48 Fox EM, Davis RJ, Shupnik MA. ERbeta in breast cancer: onlooker, passive player, or active protector? Steroids. 2008;73(11):103951.

49 Roger P, Sahla ME, Mäkelä S, Gustafsson JA, Baldet P, Rochefort H. Decreased expression of estrogen receptor beta protein in proliferative preinvasive mammary tumors. Cancer Res. 2001;61(6):2537-41.

50 Gerner EW, Meyskens FL. Polyamines and cancer: old molecules, new understanding. Nat Rev Cancer. 2004;4(10):781-92.

51 Thomas T, Thomas TJ. Polyamine metabolism and cancer. J Cell Mol Med. 2003;7(2): $113-26$.

52 Zell JA, Ziogas A, Ignatenko N, Honda J, Qu $\mathrm{N}$, Bobbs AS, et al. Associations of a polymorphism in the ornithine decarboxylase gene with colorectal cancer survival. Clin Cancer Res. 2009;15(19):6208-16.
53 Abulí A, Bessa X, González JR, Ruiz-Ponte C, Cáceres A, Muñoz J, et al. Susceptibility genetic variants associated with colorectal cancer risk correlate with cancer phenotype. Gastroenterology. 2010;139(3):788-6.

54 Wright JB, Brown SJ, Cole MD. Upregulation of c-MYC in cis through a large chromatin loop linked to a cancer risk-associated singlenucleotide polymorphism in colorectal cancer cells. Mol Cell Biol. 2010;30(6):1411-20.

55 Tuupanen S, Turunen M, Lehtonen R, Hallikas O, Vanharanta S, Kivioja T, et al. The common colorectal cancer predisposition SNP rs6983267 at chromosome 8q24 confers potential to enhanced Wnt signaling. Nat Genet. 2009;41(8):885-90.

56 Takatsuno Y, Mimori K, Yamamoto K, Sato T, Niida A, Inoue H, et al. The rs6983267 SNP is associated with MYC transcription efficien$\mathrm{cy}$, which promotes progression and worsens prognosis of colorectal cancer. Ann Surg Oncol. 2013;20(4):1395-402.

57 Rochlitz CF, Herrmann R, De Kant E. Overexpression and amplification of c-myc during progression of human colorectal cancer. Oncology. 1996;53(6):448-54.

58 Haerian MS, Baum L, Haerian BS. Association of $8 \mathrm{q} 24.21$ loci with the risk of colorectal cancer: a systematic review and meta-analysis. J Gastroenterol Hepatol. 2011;26(10): 1475-84.

59 Sugimachi K, Niida A, Yamamoto K, Shimamura $\mathrm{T}$, Imoto $\mathrm{S}$, Iinuma $\mathrm{H}$, et al. Allelic imbalance at an 8q24 oncogenic SNP is involved in activating MYC in human colorectal cancer. Ann Surg Oncol. 2014;21(Suppl 4): S515-21.

60 von Levetzow C, Jiang X, Gwye Y, von Levetzow G, Hung L, Cooper A, et al. Modeling initiation of ewing sarcoma in human neural crest cells. PLoS One. 2011;6(4):e19305.

61 Tirode F, Laud-Duval K, Prieur A, Delorme B, Charbord P, Delattre O. Mesenchymal stem cell features of Ewing tumors. Cancer Cell. 2007;11(5):421-9.

62 Delattre O, Zucman J, Plougastel B, Desmaze C, Melot T, Peter M, et al. Gene fusion with an ETS DNA-binding domain caused by chromosome translocation in human tumours. Nature. 1992;359(6391):162-5.

63 Delattre O, Zucman J, Melot T, Garau XS, Zucker JM, Lenoir GM, et al. The Ewing family of tumors: a subgroup of small-round-cell tumors defined by specific chimeric transcripts. N Engl J Med. 1994;331(5):294-9.

64 Gangwal K, Sankar S, Hollenhorst PC, Kinsey M, Haroldsen SC, Shah AA, et al. Microsatellites as EWS/FLI response elements in EWing's sarcoma. Proc Natl Acad Sci U S A. 2008; 105(29):10149-54.

65 Guillon N, Tirode F, Boeva V, Zynovyev A, Barillot E, Delattre O. The oncogenic EWSFLI1 protein binds in vivo GGAA microsatellite sequences with potential transcriptional activation function. PLoS One. 2009;4(3): e4932. 
66 Postel-Vinay S, Véron AS, Tirode F, Pierron G, Reynaud S, Kovar H, et al. Common variants near TARDBP and EGR2 are associated with susceptibility to Ewing sarcoma. Nat Genet. 2012;44(3):323-7.

67 Grünewald TG, Bernard V, Gilardi-Hebenstreit P, Raynal V, Surdez D, Aynaud MM, et al. Chimeric EWSR1-FLI1 regulates the Ewing sarcoma susceptibility gene EGR2 via a GGAA microsatellite. Nat Genet. 2015;47(9): 1073-8.

68 Trédaniel J, Boffetta P, Buiatti E, Saracci R, Hirsch A. Tobacco smoking and gastric cancer: review and meta-analysis. Int J Cancer. 1997;72(4):565-73.

69 Oh DY, Choi KS, Shin HR, Bang YJ. Public awareness of gastric cancer risk factors and disease screening in a high risk region: a population-based study. Cancer Res Treat. 2009; 41(2):59-66.

70 González CA, Sala N, Capellá G. Genetic susceptibility and gastric cancer risk. Int J Cancer. 2002;100(3):249-60.

71 Hanahan D, Weinberg RA. Hallmarks of cancer: the next generation. Cell. 2011;144(5): 646-74.

72 Lu P, Weaver VM, Werb Z. The extracellular matrix: a dynamic niche in cancer progression. J Cell Biol. 2012;196(4):395-406.

73 Ghilardi G, Biondi ML, Erario M, Guagnellini E, Scorza R. Colorectal carcinoma susceptibility and metastases are associated with matrix metalloproteinase-7 promoter polymorphisms. Clin Chem. 2003;49(11):1940-2.

74 Shi M, Liu D, Duan H, Han C, Wei B, Qian L, et al. Catecholamine up-regulates MMP-7 expression by activating AP-1 and STAT3 in gastric cancer. Mol Cancer. 2010;9:269.

75 Honda M, Mori M, Ueo H, Sugimachi K, Akiyoshi T. Matrix metalloproteinase-7 expression in gastric carcinoma. Gut. 1996;39(3): 444-8.

76 Chuang HC, Su CY, Huang HY, Huang CC, Chien CY, Du YY, et al. Active matrix metalloproteinase-7 is associated with invasion in buccal squamous cell carcinoma. Mod Pathol. 2008;21(12):1444-50.

77 Ii M, Yamamoto H, Adachi Y, Maruyama Y, Shinomura Y. Role of matrix metalloproteinase-7 (matrilysin) in human cancer invasion, apoptosis, growth, and angiogenesis. Exp Biol Med. 2006;231(1):20-7.

78 Kesh K, Subramanian L, Ghosh N, Gupta V, Gupta A, Bhattacharya S, et al. Association of MMP7-181A $\rightarrow \mathrm{G}$ promoter polymorphism with gastric cancer risk: influence of nicotine in differential allele-specific transcription via increased phosphorylation of cAMP-response element-binding protein (CREB). J Biol Chem. 2015;290(23): 14391-406.

79 Meyer KB, Maia AT, O’Reilly M, Ghoussaini M, Prathalingam R, Porter-Gill P, et al. A functional variant at a prostate cancer predisposition locus at $8 \mathrm{q} 24$ is associated with PVT1 expression. PLoS Genet. 2011;7(7):e1002165.
80 Huang Q, Whitington T, Gao P, Lindberg JF, Yang Y, Sun J, et al. A prostate cancer susceptibility allele at 6q22 increases RFX6 expression by modulating HOXB13 chromatin binding. Nat Genet. 2014;46(2):126-35.

81 Gao P, Xia JH, Sipeky C, Dong XM, Zhang Q, Yang Y, et al. Biology and clinical implications of the 19q13 aggressive prostate cancer susceptibility locus. Cell. 2018;174(3):576-89. e18.

82 Amin Al Olama A, Kote-Jarai Z, Schumacher FR, Wiklund F, Berndt SI, Benlloch S, et al. A meta-analysis of genome-wide association studies to identify prostate cancer susceptibility loci associated with aggressive and nonaggressive disease. Hum Mol Genet. 2013; 22(2):408-15

83 Blumenthal RD, Leon E, Hansen HJ, Goldenberg DM. Expression patterns of CEACAM5 and CEACAM6 in primary and metastatic cancers. BMC Cancer. 2007;7:2.

84 Nanda N, Bao M, Lin H, Clauser K, Komuves $\mathrm{L}$, Quertermous T, et al. Platelet endothelial aggregation receptor 1 (PEAR1), a novel epidermal growth factor repeat-containing transmembrane receptor, participates in platelet contact-induced activation. J Biol Chem. 2005;280(26):24680-9.

85 Faraday N, Yanek LR, Yang XP, Mathias R, Herrera-Galeano JE, Suktitipat B, et al. Identification of a specific intronic PEAR1 gene variant associated with greater platelet aggregability and protein expression. Blood. 2011; 118(12):3367-75

86 Lewis JP, Ryan K, O’Connell JR, Horenstein RB, Damcott CM, Gibson Q, et al. Genetic variation in PEAR1 is associated with platelet aggregation and cardiovascular outcomes. Circ Cardiovasc Genet. 2013;6(2):184-92.

87 Koch WJ, Rockman HA, Samama P, Hamilton R, Bond RA, Milano CA, et al. Cardiac function in mice overexpressing the $\beta$-adrenergic receptor kinase or a $\beta$ ARK inhibitor. Science. 1995;268(5215):1350-3.

88 Klenke S, Engler A, Ecker D, Ochsenfarth C, Danowski N, Peters J, et al. The GRK2 promoter is regulated by early-growth response transcription factor EGR-1. Basic Clin Pharmacol Toxicol. 2018;123(6):660-9.

89 Khachigian LM. Early growth response- 1 in cardiovascular pathobiology. Circ Res. 2006; 98(2):186-91.

90 Park S, Lu KT, Liu X, Chatterjee TK, Rudich SM, Weintraub NL, et al. Allele-specific expression of angiotensinogen in human subcutaneous adipose tissue. Hypertension. 2013; 62(1):41-7.

91 Dickson ME, Sigmund CD. Genetic basis of hypertension: revisiting angiotensinogen. Hypertension. 2006;48(1):14-20.

92 Ehret GB, Ehret GB, Munroe PB, Rice KM, Bochud M, Johnson AD, et al. Genetic variants in novel pathways influence blood pressure and cardiovascular disease risk. Nature. 2011;478(7367):103-9.
93 Somlyo AP, Somlyo AV. Signal transduction through the RhoA/Rho-kinase pathway in smooth muscle. J Muscle Res Cell Motil. 2004;25(8):613-5.

94 Bai X, Mangum KD, Dee RA, Stouffer GA, Lee CR, Oni-Orisan A, et al. Blood pressureassociated polymorphism controls ARHGAP42 expression via serum response factor DNA binding. J Clin Invest. 2017;127(2): 670-80.

95 Nielsen LB, Perko M, Arendrup H, Andersen CB. Microsomal triglyceride transfer protein gene expression and triglyceride accumulation in hypoxic human hearts. Arterioscler Thromb Vasc Biol. 2002;22(9): 1489-94.

96 Shoulders CC, Shelness GS. Current biology of MTP: implications for selective inhibition. Curr Top Med Chem. 2005;5(3):283300

97 Aminoff A, Ledmyr H, Thulin P, Lundell K, Nunez L, Strandhagen E, et al. Allele-specific regulation of MTTP expression influences the risk of ischemic heart disease .J Lipid Res. 2010;51(1):103-11.

98 Dritsoula A, Papaioannou I, Guerra SG, Fonseca C, Martin J, Herrick AL, et al. Molecular basis for dysregulated activation of NKX2-5 in the vascular remodeling of systemic sclerosis. Arthritis Rheumatol. 2018; 70(6):920-31.

99 Paffett-Lugassy N, Singh R, Nevis KR, Guner-Ataman B, O’Loughlin E, Jahangiri L, et al. Heart field origin of great vessel precursors relies on nkx2.5-mediated vasculogenesis. Nat Cell Biol. 2013;15(11):1362-9.

100 Nagelberg D, Wang J, Su R, Torres-Vázquez J, Targoff KL, Poss KD, et al. Origin, specification, and plasticity of the great vessels of the heart. Curr Biol. 2015;25(16):2099-110.

101 Ponticos M, Partridge T, Black CM, Abraham DJ, Bou-Gharios G. Regulation of collagen type I in vascular smooth muscle cells by competition between $\mathrm{Nkx} 2.5$ and deltaEF1/ZEB1. Mol Cell Biol. 2004;24(14) 6151-61.

102 Ponticos M, Jackson C, Bou-Gharios G, Abraham D. The role of the homeobox transcription factor NKX2.5 in the regulation of collagen in vessels and in the atherosclerotic lesion. Vasc Pharmacol. 2006;45(3):e45-6.

103 Imamura M, Maeda S. Genetics of type 2 diabetes: the GWAS era and future perspectives [Review]. Endocr J. 2011;58(9):723-39.

104 Kubaszek A, Pihlajamäki J, Komarovski V, Lindi V, Lindström J, Eriksson J, et al. Promoter polymorphisms of the TNF-alpha (G$308 \mathrm{~A})$ and IL-6 (C-174G) genes predict the conversion from impaired glucose tolerance to type 2 diabetes: the Finnish Diabetes Prevention Study. Diabetes. 2003;52(7):1872-6.

105 Susa S, Daimon M, Sakabe J, Sato H, Oizumi T, Karasawa S, et al. A functional polymorphism of the TNF-alpha gene that is associated with type $2 \mathrm{DM}$. Biochem Biophys Res Commun. 2008;369(3):943-7. 
106 Kameswaran V, Golson ML, Ramos-Rodríguez M, Ou K, Wang YJ, Zhang J, et al. The dysregulation of the DLK1-MEg3 locus in islets from patients with type 2 diabetes is mimicked by targeted epimutation of its promoter with TALE-DNMT constructs. Diabetes. 2018;67(9):1807-15.

107 Kameswaran V, Bramswig NC, McKenna LB, Penn M, Schug J, Hand NJ, et al. Epigenetic regulation of the DLK1-MEG3 MicroRNA cluster in human type 2 diabetic islets. Cell Metab. 2014;19(1):135-45.

108 Nalls MA, Pankratz N, Lill CM, Do CB, Hernandez DG, Saad M, et al. Large-scale metaanalysis of genome-wide association data identifies six new risk loci for Parkinson's disease. Nat Genet. 2014;46(9):989-93.

109 Soldner F, Stelzer Y, Shivalila CS, Abraham BJ, Latourelle JC, Barrasa MI, et al. Parkinson-associated risk variant in distal enhancer of $\alpha$-synuclein modulates target gene expression. Nature. 2016;533(7601):95-9.

110 Smith AK, Dimulescu I, Falkenberg VR, Narasimhan S, Heim C, Vernon SD, et al. Genetic evaluation of the serotonergic system in chronic fatigue syndrome. Psychoneuroendocrinology. 2008;33(2):188-97.

111 Falkenberg VR, Gurbaxani BM, Unger ER, Rajeevan MS. Functional genomics of serotonin receptor 2A (HTR2A): interaction of polymorphism, methylation, expression and disease association. NeuroMolecular Med. 2011;13(1):66-76.

112 Hawkins NJ, Lee JH, Wong JJ, Kwok CT, Ward RL, Hitchins MP. MGMT methylation is associated primarily with the germline C>T SNP (rs16906252) in colorectal cancer and normal colonic mucosa. Mod Pathol. 2009;22(12):1588-99.

113 Rapkins RW, Wang F, Nguyen HN, Cloughesy TF, Lai A, Ha W, et al. The MGMT promoter SNP rs16906252 is a risk factor for MGMT methylation in glioblastoma and is predictive of response to temozolomide. Neuro-oncology. 2015;17(12):1589-98.

114 Leng S, Bernauer AM, Hong C, Do KC, Yingling $\mathrm{CM}$, Flores $\mathrm{KG}$, et al. The $\mathrm{A} / \mathrm{G}$ allele of Rs16906252 predicts for MGMT methylation and is selectively silenced in premalignant lesions from smokers and in lung adenocarcinomas. Clin Cancer Res. 2011;17(7): 2014-23.

115 Ross-Adams H, Ball S, Lawrenson K, Halim S, Russell R, Wells C, et al. HNF1B variants associate with promoter methylation and regulate gene networks activated in prostate and ovarian cancer. Oncotarget. 2016;7(46): 74734-46.

116 Shi Y, Xu L, Feng Q, Li A, Jia J, Xu Y, et al. Allele-specific methylation contributed by CpG-SNP is associated with regulation of ALOX5AP gene expression in ischemic stroke. Neurol Sci. 2018;39(10):1717-24.
117 Prasad RB, Lessmark A, Almgren P, Kovacs G, Hansson O, Oskolkov N, et al. Excess maternal transmission of variants in the THADA gene to offspring with type 2 diabetes. Diabetologia. 2016;59(8):1702-13.

118 Polesskaya OO, Aston C, Sokolov BP. Allele C-specific methylation of the 5-HT2A receptor gene: evidence for correlation with its expression and expression of DNA methylase DNMT1. J Neurosci Res. 2006;83(3): 362-73.

119 Schieck M, Sharma V, Michel S, Toncheva AA, Worth L, Potaczek DP, et al. A polymorphism in the TH 2 locus control region is associated with changes in DNA methylation and gene expression. Allergy. 2014; 69(9):1171-80.

120 Deng G, Chen A, Hong J, Chae HS, Kim YS Methylation of $\mathrm{CpG}$ in a small region of the hMLH1 promoter invariably correlates with the absence of gene expression. Cancer Res. 1999;59(9):2029-33.

121 Fennell LJ, Jamieson S, McKeone D, Corish T, Rohdmann M, Furner T, et al. MLH1-93 $\mathrm{G} / \mathrm{a}$ polymorphism is associated with MLH1 promoter methylation and protein loss in dysplastic sessile serrated adenomas with BRAFV600E mutation. BMC Cancer. 2018; 18(1):35.

122 Saetrom P, Biesinger J, Li SM, Smith D, Thomas LF, Majzoub K, et al. A risk variant in an miR-125b binding site in BMPR1B is associated with breast cancer pathogenesis. Cancer Res. 2009;69(18):7459-65.

123 Zheng J, Huang X, Tan W, Yu D, Du Z, Chang J, et al. Pancreatic cancer risk variant in LINC00673 creates a miR-1231 binding site and interferes with PTPN11 degradation. Nat Genet. 2016;48(7):747-57.

124 Richardson K, Nettleton JA, Rotllan N, Tanaka T, Smith CE, Lai CQ, et al. Gain-offunction lipoprotein lipase variant rs13702 modulates lipid traits through disruption of a microRNA-410 seed site. Am J Hum Genet. 2013;92(1):5-14.

125 Miller CL, Haas U, Diaz R, Leeper NJ, Kundu RK, Patlolla B, et al. Coronary heart disease-associated variation in TCF21 disrupts a miR-224 binding site and miRNA-mediated regulation. PLoS Genet. 2014;10(3): e1004263.

126 Ghanbari M, Franco OH, De Looper HW, Hofman A, Erkeland SJ, Dehghan A. Genetic variations in MicroRNA-binding sites affect microRNA-mediated regulation of several genes associated with cardio-metabolic phenotypes. Circ Cardiovasc Genet. 2015; 8(3):473-86.
127 Teng MS, Hsu LA, Juan SH, Lin WC, Lee MC, Su CW, et al. A GDF15 3' UTR variant, rs1054564, results in allele-specific translational repression of GDF15 by hsa-miR1233-3p. PLoS One. 2017;12(8):e0183187.

$128 \mathrm{Wu}$ C, Arora P, Agha O, Hurst LA, Allen K, Nathan DI, et al. Novel microRNA regulators of atrial natriureticpeptide production. Mol Cell Biol. 2016;36(14):1977-87.

129 Hou Y, Liang W, Zhang J, Li Q, Ou H, Wang $\mathrm{Z}$, et al. Schizophrenia-associated rs4702 G allele-specific downregulation of FURIN expression by miR-338-3p reduces BDNF production. Schizophr Res. 2018;199:176-80.

130 Zhang G, Li N, Li Z, Zhu Q, Li F, Yang C, et al. microRNA-4717 differentially interacts with its polymorphic target in the PD1 3' untranslated region: a mechanism for regulating PD-1 expression and function in HBVassociated liver diseases. Oncotarget. 2015; 6(22):18933-44.

131 Knox B, Wang Y, Rogers LJ, Xuan J, Yu D, Guan $\mathrm{H}$, et al. A functional SNP in the $3^{\prime}$ UTR of TAP2 gene interacts with microRNA hsa-miR-1270 to suppress the gene expression. Environ Mol Mutagen. 2018;59(2): $134-43$.

132 Wang H, Lou D, Wang Z. Crosstalk of genetic variants, allele-specific DNA methylation, and environmental factors for complex disease risk. Front Genet. 2019;9:1-15.

133 Maloney R, Budiman M, Korshunova Y, Monte J, Bacher B, Lakey N, et al. Tissuespecific DNA methylation patterns are frequent targets of epigenetic change in multiple cancer types. Cancer Res. 2008;68(9 Suppl):LB-256.

134 Marsit CJ. Influence of environmental exposure on human epigenetic regulation. J Exp Biol. 2015;218(Pt 1):71-9.

135 Reuter JA, Spacek DV, Snyder MP. Highthroughput sequencing technologies. $\mathrm{Mol}$ Cell. 2015;58(4):586-97.

136 Huang T, Shu Y, Cai YD. Genetic differences among ethnic groups. BMC Genomics. 2015;16:1093.

137 Hoareau-Aveilla C, Meggetto F. Crosstalk between microRNA and DNA methylation offers potential biomarkers and targeted therapies in ALK-positive lymphomas. Cancers. 2017;9(8):100.

138 Buroker NE. Regulatory SNPs and transcriptional factor binding sites in ADRBK1, AKT3, ATF3, DIO2, TBXA2R and VEGFA. Transcription. 2014;5(4):e964559.

139 Zhi D, Aslibekyan S, Irvin MR, Claas SA Borecki IB, Ordovas JM, et al. SNPs located at $\mathrm{CpG}$ sites modulate genome-epigenome interaction. Epigenetics. 2013;8(8):802-6. 